American J. of Engineering and Applied Sciences 4 (1): 82-88, 2011

ISSN 1941-7020

(C) 2010 Science Publications

\title{
Roughness Effect on an Unsteady Flow in Pipelines by Profilometry and Imaging Techniques
}

\author{
${ }^{1}$ Mabrouk Benkhedimallah, ${ }^{2}$ Rabah Zegadi and ${ }^{3}$ Mohamed Bouafia \\ ${ }^{1}$ Laboratory of Chemical Process Engineering, \\ ${ }^{2}$ Laboratory of Patron Applied Precision, \\ ${ }^{3}$ Laboratory of Applied Optics, \\ Technology Department, Faculty of Technology, University of Setif, 19000 Setif, Algeria
}

\begin{abstract}
Problem statement: Currently the aero dynamical calculation in gas pipes is carried out under the assumption of steady state conditions. However real steady in a network is scarcely quasisteady. Approach: The unsteady state is governed by non-linear partial differential equations leading to mathematical difficulties. And there are fore gas pipe dimensions are computed at steady state under extreme conditions. Results: In order to precisely describe gas flow closely to real conditions, we suggest characterizing roughness of two pieces removed during the repair of damaged pipes from a gas transport network. Samples roughness characterization is carried out by profilometry (using a stylus instrument) and by imaging techniques procedures to show the roughness effect and its impact for dynamic flow state. In order to approach real conditions, we considered real cases to construct a model and then we proceeded through extensive simulation for twenty four hours to build graphical means for comparing measurement and computed data. Conclusion/Recommendations: The obtained results are in good agreement with those of imaging analysis and in our interpretation we express that during dynamic flow at high rates gas energy lose due to friction inner walls is characterized this loose are more important as the flow is turbulent. Differences are shown between real data values and figures usually exploited. Design and parameter settings of network should be carried out after a thorough dynamical flow study.
\end{abstract}

Key words: Unsteady flow, gas pipeline, roughness, profilometry, phenomena, turbulent, Colebrook formula, Reynolds number

\section{INTRODUCTION}

Gas transport systems are too greedy of energy, especially at the level of compression stations where the amount of the consumed energy is important. An optimizing design has been tested in networks simulation of mean complexity, involving up to seven compression stations, which led to a reduction of gas consuming of about 20\% (Schmidt et al., 1978). A good design of these networks leads to a better profitability in order to optimize their operations with a more interesting cost-effectiveness rate. The study of pressure drop due to roughness in the unsteady flow of an incompressible fluid flowing through a pipe allows a better understanding of the phenomena generated during the flow of fluid while transporting it from one point to another (Farshad et al., 1999; Colebrook and White, 1937; Dyuti et al., 2010; Hurst and Wilkins, 2005; Kairouani and Nehdi, 2005; Karakosta et al., 2008; Kunert and Otegui, 2005; Mehedi et al., 2005).
We know that in pipe of large diameter, much greater than the roughness height (as the case of pipelines), the roughness has practically no effect on the pressure drop when the flow regime is laminar, on the contrary in turbulent flow, the roughness of pipes' internal surfaces causes the increase of the turbulence phenomenon. Laboratory tests cannot simulate this very complex phenomenon satisfactorily. The problem is highly non-linear and has no known analytical solution. In this analysis not only do we consider the gas flow regime but the Owen parameters of the system as well, namely the most important are the roughness and the friction factor.

The unsteady flow regime is described by nonlinear partial derivative equations bringing up therefore mathematical difficulties. Thus, dimensions of gas pipes are evaluated for the steady flow regime at extreme conditions of use. The study of the roughness and the friction factor effect on unstudy flow of a compressible fluid in a pipe relevant to many important questions about safety and the speed flow provided by

Corresponding Author: Mabrouk Benkhedimallah, Laboratory of Chemical Process Engineering, Team dynamics of gas, Technology Department, Faculty of Technology, University of Setif, 19000 Setif, Algeria 
the pipeline. In this study we try to determine experimentally from scrap (splinter) drawn during pipeline repairs after faults on the network (pipelines burs) the effect of roughness in the calculation of pressure drop in a system of natural gas pipes with a flow rate varying with time (Bradshaw, 2000).

At first we characterize the roughness of the two samples by profilometry using a stylus instrument and analyzed then by imaging techniques (Gioia et al., 2006). By mean of a simulation software we determine the pressure drop for twenty-four hours in sections from which the two studied fragments are taken. The software used is the « LIWACOM » of Simone.

\section{MATERIALS AND METHODS}

Mathematical assumptions: The complete mathematical description of the permanent compressible flow in a cylindrical gas duct (Fig. 1) is done using Bernoulli's differential equations (1)Conservation of mass, (2)- conservation of momentum, (3)-Conservation of energy, (4)-pressure) and (5)-the first principle of thermodynamics as follows:

$$
\begin{aligned}
& \frac{\partial \rho}{\partial t}+\frac{\partial}{\partial x}(\rho v)=0 \\
& \frac{\partial}{\partial t}(\rho v S)+\frac{\partial}{\partial x}\left(p S+\rho v^{2} S\right)+|\tau| \pi D+\rho S \sin \theta=0 \\
& \frac{\partial}{\partial t}\left[\left(e+\frac{1}{2} v^{2}\right) \rho S\right]+\frac{\partial}{\partial x}\left[\left(h+\frac{1}{2} v^{2}\right) \rho v S\right] \\
& -\Omega+\rho S g v \sin \theta=0 \\
& P=\rho Z R_{g} T \\
& d U+d K=d W+d Q
\end{aligned}
$$

This equation for the space and time dependent density $\rho(x, t)$ pressure $P(x, t)$ speed $v(x, t)$ and temperature $\mathrm{T}(\mathrm{x}, \mathrm{t})$ are showing in Eq. 2 .

Since the system has three equations and four unknown variables, it is necessary an additional equation to have a complete system. This indeed the gas state equation shown in Eq. 5.

In order to solve Eq. 1 and 2 it is necessary to know the value of the thermal term $\Omega$.

There are two especially important cases:

- Isothermal flow ( $\mathrm{T}=$ constant), where the energy equation becomes redundant except for calculate the value of $\Omega$

- Adiabatic flow $(\Omega=0)$, that includes the particular isentropic flow case

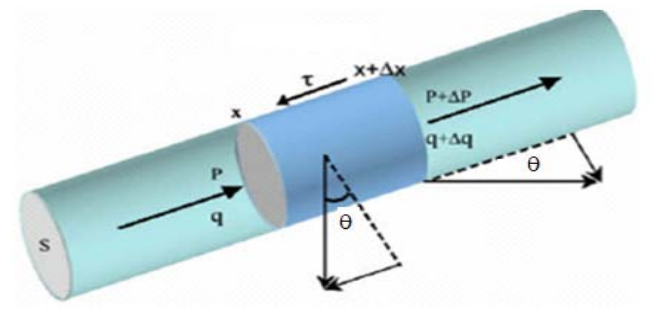

Fig.1: Control volume in a gas pipeline

If one neglects the heat transfers between gas and the exterior medium, the equation of Bernoulli is sufficient to describe the gas flow. The establishment of the generalized equation of Bernoulli is done by applying the fundamental principle of dynamics to a gas element moving in a pipe. The principal assumptions are then permanent flow, the density, the pressure and the speed of gas in a cross-section of the pipe.

S-being the cross- section area of the pipe, the gas flow of mass $\mathrm{dm}=\rho \mathrm{d} \mathrm{x}$ is subjected according to axis $\mathrm{x}$ (direction of the flow) to the following forces.

Pressure force on the upstream face $\mathrm{p}$. S pressure force on the downstream face $-p\left[p+\frac{\partial p}{\partial x}\right] S$, Gravity force $-g \frac{d h}{d x} d m$, force of contact with the wall due to the tangential strain $-\tau \pi \mathrm{Dx}$ with:

$\tau=-\mu \frac{d v}{d m}$

By applying the fundamental principle of dynamics and by introducing the friction factor $\lambda$ defined by the relation:

$$
\tau=\frac{\lambda}{4} \rho \frac{v^{2}}{2}
$$

We get then Eq. 6 and 7:

$\mathrm{dm} \frac{\mathrm{d} v}{\mathrm{dt}}=\mathrm{ps}-\left[\mathrm{p}+\frac{\mathrm{dp}}{\mathrm{dx}} \mathrm{dx}\right] \mathrm{S}-\mathrm{g} \frac{\mathrm{dh}}{\mathrm{dx}} \mathrm{dm}-\tau \pi \mathrm{Dd}$

and:

$\frac{\mathrm{dp}}{\rho}+\frac{\mathrm{gdh}}{\rho}+v \mathrm{~d} v=-\lambda \frac{v^{2}}{2 \mathrm{D}} \mathrm{dx}$

The function $\lambda=\mathrm{f}(\mathrm{p}, \rho, \gamma, v, \mathrm{R} \alpha, \mathrm{D})$ is related to six physical sizes deriving from three (3) fundamental units. It can thus be brought back according to the 
Am. J. Engg. \& Applied Sci., 4 (1): 82-88, 2011

theorem of Vaschny Buckingham to a relation between no dimensional sizes as follows Eq. 8:

$\lambda=\varphi\left[\frac{\mathrm{p}}{\rho v^{2}}, \mathrm{R}_{\mathrm{e}}, \frac{\mathrm{R}_{\alpha}}{\mathrm{D}}\right]$

where, $R_{e}$ indicates the Reynolds number and $R_{\alpha}$ the roughness.

In the case of the transport of gas in drain, the first term can be neglected. It results from it that the friction factor can be written as Eq. 9:

$$
\lambda=\varphi\left[\mathrm{R}_{\mathrm{e}}, \frac{\mathrm{R}_{\alpha}}{\mathrm{D}}\right]
$$

Methods for finding the friction factor $\lambda$ are to use a diagram, the Colebrook-White equation, or the Swamee-Jain equation. While the diagram and Colebrook-White equation are iterative solutions, the Swamee-Jain equation allows $\lambda$ to be found directly for full flow in a circular pipe.

The Colebrook equation is an implicit equation with experimental results of studies of laminar and turbulent flow in pipes. Due to the implicit nature of the Colebrook equation, determination of friction factor requires some iteration or a numerical solving method.

The Swamee-Jain equation is used to solve directly for the Darcy-Weisbach friction factor for full-flowing circular pipe. It is an approximation of the implicit Colebrook-White Eq. 10:

$$
\lambda=\frac{025}{\left[\log \left(\frac{\mathrm{R}_{\alpha}}{3.7 \mathrm{D}}+\frac{5.74}{\mathrm{R}_{\mathrm{e}}^{0.9}}\right)\right]^{2}}
$$

where, $\lambda$ is function of roughness height $R_{\alpha}$, pipe diameter $\mathrm{D}$ and Reynolds Number $\mathrm{R}_{\mathrm{e}}$ e-Specific internal energy $\left(\mathrm{JKg}^{-1}\right)$ g-Acceleration due to gravity $\left(\mathrm{m} \mathrm{sec}^{-2}\right)$ $\mathrm{h}$-Specific enthalpy, $\mathrm{h}=\mathrm{e}+\mathrm{p} / \mathrm{py}\left(\mathrm{JKg}^{-1}\right)$ M-Molecular mass of gas $\left(\mathrm{Kg} \mathrm{mol}^{-1}\right)$ $\mathrm{P}$-Gas pressure along the streamline (bar)

R-Universal gas constant $\left(\mathrm{J} \mathrm{mol}^{-1} \mathrm{~K}^{-1}\right)$

Rs-Specific constant of gas Rs $=\mathrm{R} / \mathrm{M}\left(\mathrm{JKg}^{-1} \mathrm{~K}^{-1}\right)$

$\mathrm{R}_{\mathrm{e}}$-Reynolds number (unitless)

S-Gas pipeline cross- sectional area $\left(\mathrm{m}^{2}\right)$

$\mathrm{T}$-Temperature of the gas $(\mathrm{K})$

V-Gas velocity along the streamline $\left(\mathrm{m} \mathrm{sec}^{-1}\right)$
Z-Compressibility factor

$\tau$-Tangential stress between gas and the inner wall of gas duct and $(\mathrm{N})$

$\Omega$-Heat transfer between the gas and its surroundings per unit length $\left(\mathrm{Jm}^{-1} \mathrm{~S}^{-1}\right)$

$\rho$-Gas density $\left(\mathrm{K} \mathrm{gm}^{-3}\right)$

$\lambda$-Friction factor (unitless)

$\varepsilon$-Darcy-Weisbach rougness height (m)

\section{RESULTS AND DISCUSSION}

The investigated work pieces were taken from the gas pipelines of $\mathrm{A}$ and $\mathrm{B}$ respectively. The system considered includes two networks of gas pipeline 16 "and 8 "connected to the level of the station.

Workpiece A: The choice of the experimental field was fixed on the pipeline with a diameter of about 208 $\mathrm{mm}$ and $19345 \mathrm{~m}$ length which transports gas under a pressure of 20 bars (Fig. 2).

The beginning a principal valve makes it possible to isolate this control and to set up the experimental devices. The installation allows obtaining the desired conditions of flow.

Workpiece B: A second choice of the experimental field was fixed on the gas pipeline with a diameter of about $388 \mathrm{~mm}$ and $278.55 \mathrm{~km}$ length which transports gas under an average pressure of 55 bars (Fig. 3).

Roughness measurements: The surface roughness of the work pieces was measured using a Mitutoyo URFTEST 301.The SJ-301 detector uses the differential inductance method as used in many highend instruments (Fig. 4). The Profile detail can be seen at a resolution of up to $0.01 \mu \mathrm{m}$ for a range of $10 \mu \mathrm{m}$ in the Z-axis direction. The probe can be retracted into the drive unit after making a measurement for maximum protection against accidental damage.

The evaluation length is of about $2,5 \mathrm{~mm}$ in $\mathrm{Z}$-axis direction. The stylus used has a diamond cone with 2 $\mu \mathrm{m}$ radius and a mass of $12 \mathrm{~g}$. The contact force was $0,75 \mathrm{mN}$. The measurements have been done with automatic depending resolution range $0,05-50 \mu \mathrm{m}$. The roughness parameters witches are needed for evaluations are $R_{\alpha}$ and $R_{t}$ according to (DIN EN 150 ISO4288:1998).

Roughness measuring values-especially the vertical parameters (amplitude parameters) $R_{t}$ and $R_{\alpha}$-have a spread between -20 and $+30 \%$. A single measuring value can therefore not provide a complete statement concerning the observance of the permissible parameter tolerances. DIN EN ISO 4288 specifies the following procedure. 
Am. J. Engg. \& Applied Sci., 4 (1): 82-88, 2011

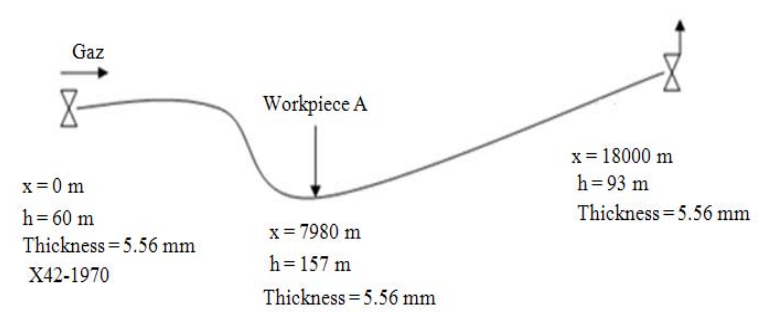

Fig. 2: system configuration relative to workpiece A

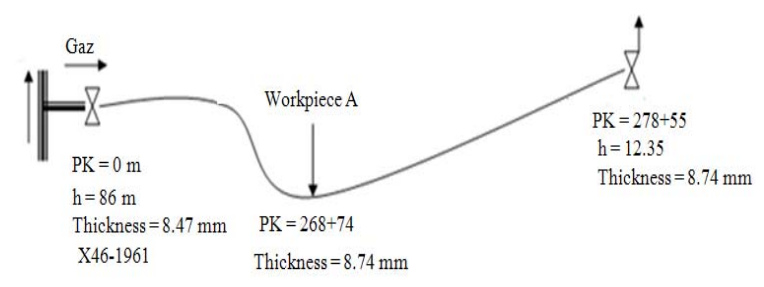

Fig. 3: system configuration relative to Workpiece B

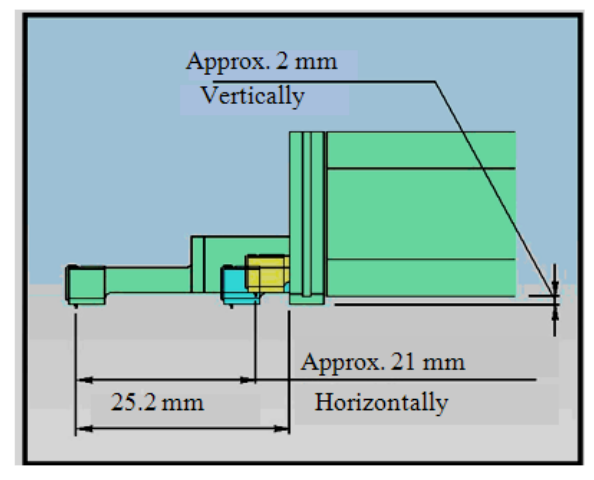

Fig. 4: Detector with used stylus

Surface roughness is usually expressed as $R_{\alpha}$ parameter. $R_{\alpha}$ is commonly referred to as the arithmetic average of all deviations from the predetermined baseline for the surface. Internal surfaces, relative roughness is the average height of surface regularities divided by the pipe diameter according to Eq. 2 the relation roughness, for pipe is $\mathrm{K}=\mathrm{R}_{\alpha} / \mathrm{D}$ (relative roughness).

Relative roughness is used to calculate the friction factor. The pressure drop due to friction can then be calculated for a pipe segment. Farshad et al. (1999) suggested that the ability of $\mathrm{R} \alpha$ to ignore intermediate height data and focus on extreme height data that would be the most likely to affect turbulent flow made it the more useful parameter compared to $\mathrm{R} \alpha$. It is also important to specify the instrument parameters used to measure the surface roughness, such as cut-off value, stylus OD and filter type. The cut-off value can be especially significant in influencing the results.

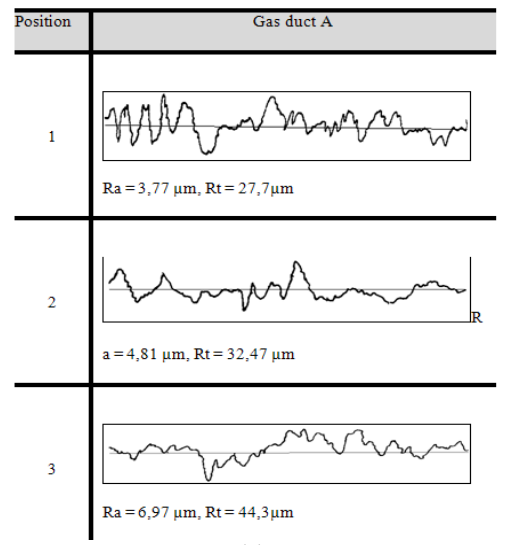

(a)

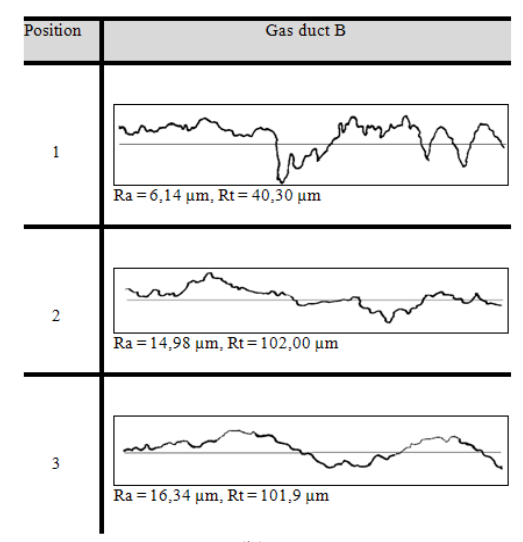

(b)

Fig. 5: Roughness profiles with arithmetic and total roughness values

Steel pipe delivered to the coating yard has a relative roughness in the order of $20 \mu \mathrm{m}$. However, once in production this relative roughness may exceed $50 \mu \mathrm{m}$, depending upon corrosion products formed on the surface due to the amount of time and conditions the pipe was stored in prior to installation, hydrostatic testing and the corrosive nature of the fluid being transported. Using hydraulic pipe flow software, the pipe roughness versus maximum achievable flow rate can be plotted, for a constant discharge and arrival pressure.

The surface profiles and the roughness values are presented in (Fig.5). The roughness profiles were registered at three positions with high pass filtering.

An unrigorous but plausible analysis suggests that the concept of a critical roughness height, below which roughness does not affect a turbulent wall flow, is erroneous. Experiments at Princeton University have revealed aspects of smooth pipe flow behavior that suggest a more complex scaling than previously noted (Bradshaw, 2000; Allen et al., 2007; Al-Rabaani and AlMekhlafi, 2009; Amin et al., 2009; Yodrak et al., 2010). 
In the following graphics, we present simulations with real data over a network transport gas. Curves obtained show a significant difference in pressure resulting from loss of loads caused by the theoretical roughness $(0.12 \mu \mathrm{m})$ and real roughness $(3.77 \mu \mathrm{m})$, especially during the time slot between eight (8) and eighteen (18) hour period corresponding to strong consumer demand for gas. These graphs have been built with the software calculating dynamic network "SIMONE" (Fig. 6)

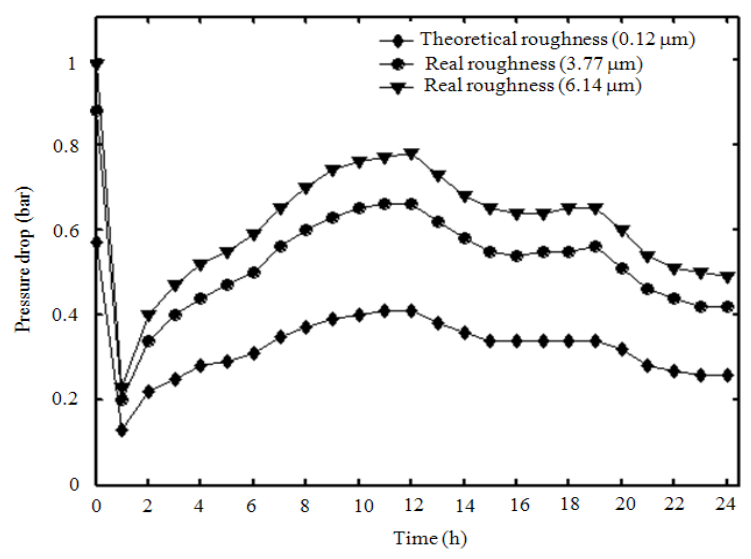

Fig. 6: Pressure drop variation versus time

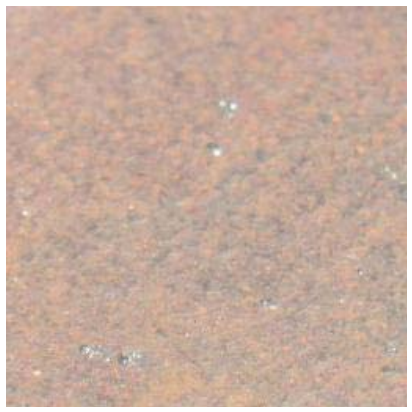

(a)

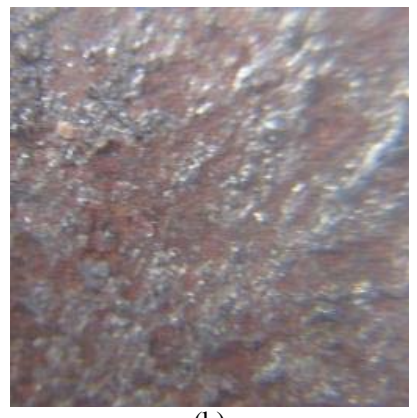

(b)

Fig. 7: Bitmap analysis: (a) Gas pipe A; (b) Gas pipe B
Image analysis: The digitization process of the acquired surface images has been applied by using pro plus bitmap analysis software. The process divides the image into horizontal array of pixels. Each pixel in the bitmap is identified by its position in the grid. That is, each pixel in the image is individually sampled and its brightness is measured and quantified. A contiguous subset of pixels defined within the image as Area of Interest "AOI" is used to isolate an area from the rest of the image (Fig. 7).

Powerful 3D image processing, enhancement and analysis have been employed to explore the depth of the images by visualizing and interacting with them in three dimensions as shown in Fig. 8. The view of the surface from $45^{\circ}$ angle, using texture mapping, pseudo coloring enhance the details for interpretation. Testing the difference between the study pieces we show how Topographic Smoothing contributes to differences between the pipes.

This is clearly demonstrated by the intensities graphs illustrated in Fig. 9. The local valleys of the profiles intensity versus distance pixels are visibly differentiable. The correlation between roughness and the bitmap analysis is highlighted. The image processing confirmed that the pipe $\mathrm{B}$ is characterized by a high roughness.

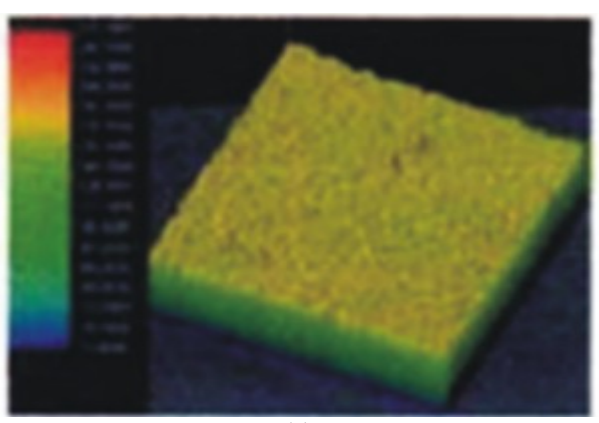

(a)

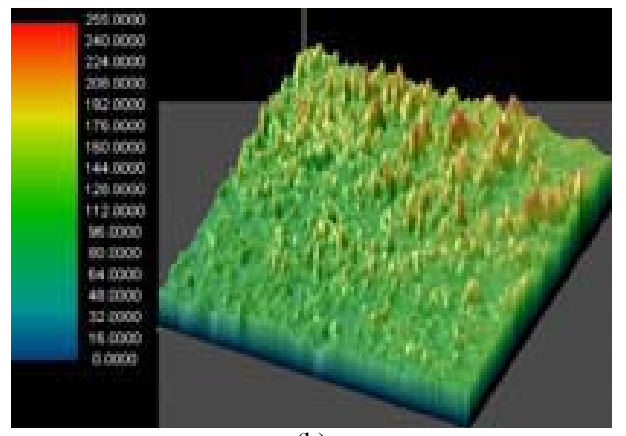

(b)

Fig. 8: 2D-plot: (a) Gas pipe A; (b) Gas pipe B 


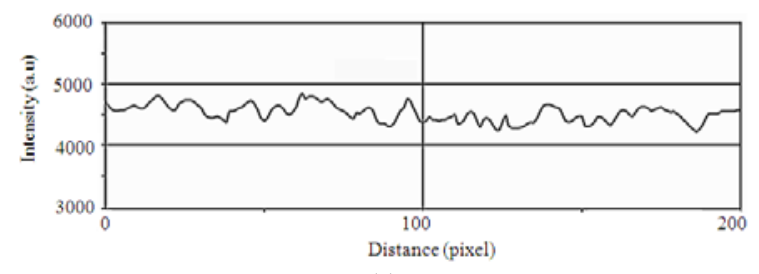

(a)

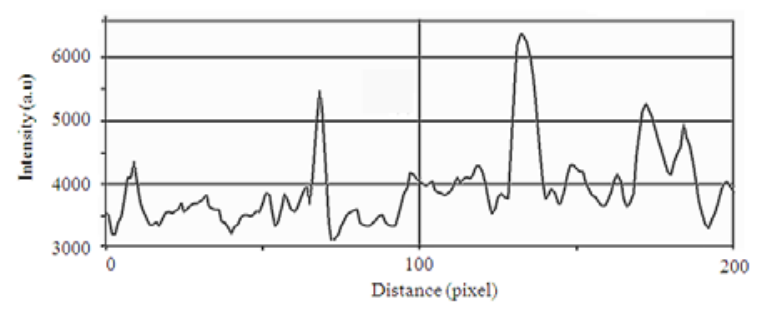

(b)

Fig. 9: Intensity versus distance pixels: (a) Gas pipe A; (b) Gas pipe B

The pressure gradient results yield a new friction factor relationship for smooth pipes, with presence of a power-law region near the wall and for Reynolds numbers greater than about $400 \times 10^{3}$, a logarithmic region further out. Experiments on a rough pipe with a hone surface finish with $\mathrm{R} \alpha / \mathrm{D}=19,4.10^{-6}$, over a Reynolds number range of $57 \times 10^{3}-21 \times 10^{6}$, show that in the transitionally rough regime this surface follows an inflectional friction factor relationship rather than the monotonic relationship given in the Moody diagram.

\section{CONCLUSION}

A flowing gas in a pipeline undergoes energy losses due to frictions on the walls, even if the pipe is horizontal and its cross-section area is uniform. The flow phenomena are very complex and pressure loss determination is usually the result of experimental measurements, which explains the diversity of expressions that are proposed for its determination.

When the flow regime is turbulent, the influence of roughness is more important as the Reynolds number is large. Colebrook formula utilization, which reflects better turbulent flow phenomena, would require calculations by approximations to determine the friction coefficient as a function of the Reynolds number and pipeline roughness. The obtained results show that for an unsteady high speed flow, loss of energy occurs due to friction on the inner walls, these losses are even more important as the flow is turbulent. The actual obtained values and the mean computed ones we study on usually in gas pipelines transport are in good agreement with the profilometry and imaging analysis.

\section{REFERENCES}

Allen, J.J., M.A. Shockling, G.J. Kunkel and A.J. Smits, 2007. Turbulent flow in smooth and rough pipes. Phil. Trans. R. Soc., 365: 699-714. DOI: $10.1098 /$ rsta.2006.1939

Al-Rabaani, A.B.H. and S.S.M. Al-Mekhlafi, 2009. Attitudes of sultan qaboos university students towards some environmental problems and their willingness to take action to reduce them. J. Soc. Sci., 5: 9-15. DOI: 10.3844/jssp.2009.9.15

Amin, A., C. Siwar and A. Hamid, 2009. Computable general equilibrium techniques for carbon tax modeling. Am. J. Environ. Sci., 5: 330-340. DOI: 10.3844/ajessp.2009.330.340

Bradshaw, P., 2000. A note on "critical roughness height" and "transitional roughness". Phy. Fluids, 12: 1611-1614. DOI: 10.1063/1.870410

Colebrook, C.F. and C.M. White, 1937. Experiments with fluid friction in roughened pipes. Proceed. Royal Soc. London. Series Math. Phy. Sci., 161: 367-381.

Dyuti, S., S. Mridha and S.K. Shaha, 2010. Surface modification of mild steel using tungsten inert gas torch surface cladding. Am. J. Environ. Sci., 7: 815-822. DOI: 10.3844/ajassp.2010.815.822

Farshad, F., T.C. Pesacreta, S.R. Bikki and R.H. Davis, 1999. Surface roughness in internally coated pipes (OCTG). Proceedings of the Offshore Technology Conference, May 3-6, Houston, Texas, pp: 9-9. DOI: $10.4043 / 11059-\mathrm{MS}$

Gioia, G. and P. Chakraborty, 2006. Turbulent friction in rough pipes and the energy spectrum of the phenomenological theory. Phys. Rev. Lett. 98: 044502-044505.

DOI: 10.1103/PhysRevLett.96.044502

Hurst, M.R. and E. Wilkins, 2005. Chemical and biological warfare: Should rapid detection techniques be researched to dissuade usage? A review. Am. J. Applied. Sci., 2: 796-805. DOI: 10.3844/ajassp.2005.796.805

Kairouani, L. and E. Nehdi, 2005. Thermodynamic analysis of an absorption/compression refrigeration system using geothermal energy. Am. J. Applied Sci., 2: 914-919. DOI: 10.3844/ajassp.2005.914.919

Karakosta, C., H. Doukas and J. Psarras, 2008. A decision support approach for the sustainable transfer of energy technologies under the kyoto protocol. Am. J. Applied Sci., 5: 1720-1729. DOI: 10.3844/ajassp.2008.1720.1729 
Kunert, H.G. and J.L. Otegui, 2005. Factors influencing transit fatigue of seamless pipes. Fatigue Fract. Eng. Mat. Struc., 28: 455-466. DOI: $10.1111 / \mathrm{j} .1460-2695.2005 .00884 . x$

Mehedi, I.M., R. Varatharajoo, H. Harun and M.N. Filipski, 2005. Architecture for combined energy and attitude control system. Am. J. Applied Sci., 2: 430-435. DOI: 10.3844/ajassp.2005.430.435

Schmidt, G., A. Weimann and G. Lappus, 1978. Application of Simulation Techniques to Planning, Supervision and Control Of Natural Gas Distribution Networks. In: Simulation, modelling and decision in energy systems, Carver, M.B. and M.H. Hamza (Eds.), Anaheim, CA: Acta Press, pp: 404-409.
Yodrak, L., S. Rittidech, N. Poomsa-ad and P. Meena, 2010. Waste heat recovery by heat pipe airpreheater to energy thrift from the furnace in a hot forging process. Am. J. Applied Sci., 7: 675-681. DOI: 10.3844/ajassp.2010.675.681 